\title{
Enzimas exógenas em dietas de frangos de corte: desempenho
}

\author{
Exogenous enzymes in broilers fed diets: performance
}

\section{Nei André Arruda Barbosa' ${ }^{\mathrm{I}}$ Nilva Kazue Sakomura ${ }^{\mathrm{I} *}$ Melina Aparecida Bonato $^{\mathrm{I}}$ Luciano Hauschild $^{\mathrm{I}}$ Edgar Oviedo-Rondon"}

\section{RESUMO}

O experimento foi conduzido para avaliar a eficiência de enzimas exógenas em dietas sobre o desempenho de frangos de corte. Um total de 1440 pintos de corte machos $\left(\right.$ Cobb 500 $\left.{ }^{\circledR}\right)$ foram distribuídos em um delineamento inteiramente casualizado em esquema fatorial $2 \times 2$ (duas dietas com diferentes densidades nutricionais; com e sem a adição enzimática) com 8 repetições de 45 aves em cada unidade experimental. As dietas com diferentes densidades nutricionais foram: controle positivo (níveis normais) e um controle negativo (com redução de 4,3 e 4,5\% de energia metabolizável; 16,7 e 17,7\% de cálcio e 35 e 42,7\% de fósforo, nas fases inicial e de crescimento, respectivamente). A suplementação enzimática consistiu da combinação das enzimas fitase $\left(100 \mathrm{~g} \mathrm{t}^{-1}\right)$ e amilase, xilanase e protease $\left(500 \mathrm{~g} \mathrm{t}^{-1}\right)$. Foi avaliado o desempenho das aves nas fases de 1 a 21 e 1 a 42 dias de idade. Na fase total de criação, as aves alimentadas com a dieta controle negativo com adição enzimática tiveram consumo de ração (5,97\%), peso médio $(8,47 \%)$, ganho de peso $(8,64 \%)$ e conversão alimentar $(2,92 \%)$ melhores $(P<0,05)$, comparados às aves alimentadas com dieta controle negativo, sem a suplementação de enzimas. Além disso, as aves alimentadas com a dieta controle negativo com adição enzimática apresentaram consumo de ração, peso vivo médio e ganho de peso similar $(P>0,05)$ ao grupo alimentado com a dieta controle positivo com ou sem enzima. A adição de enzimas exógenas em dieta de frangos de corte com redução de energia metabolizável, cálcio e fósforo, proporciona um consumo de ração, peso vivo médio e ganho de peso similar a uma dieta com níveis nutricionais adequados.

Palavras-chave: aves, fitase, amilase, protease, xilanase.

\section{ABSTRACT}

The experiment was conducted to evaluate the effect of enzyme efficiency in diets with and without nutrient reduction on the performance of broilers. Thousand and hundred forty male broiler chicks (Cobb 500 ${ }^{\circledR}$ ) were distributed in a completely randomized design with 4 treatments in a factorial $2 \times 2$ (two diets with different nutrient densities, with and without enzyme) with 8 replications of 45 birds. The diets were: positive control (normal) and a negative control (with a reduction of $4.3 \%$ and $4.5 \%$ of metabolizable energy, $16.7 \%$ and $17.7 \%$ of calcium and $35 \%$ and $42.7 \%$ of phosphorus, in initial and growth phases, respectively). The enzyme supplementation consisted of a combination of phytase enzyme $\left(100 \mathrm{~g} \mathrm{t}^{-1}\right)$ and amylase, xylanase and protease $\left(500 \mathrm{~g} \mathrm{t}^{-1}\right)$. It was evaluated the performance of birds in phases 1 to 21 and 1 to 42 days old. In the total period, the birds fed with negative control diet with added enzyme had feed intake (5.97\%), body weight (8.47\%), body weight gain $(8.64 \%)$ and feed conversion $(2.92 \%)$ higher $(P<0.05)$ than compared to birds fed with negative control diet without enzyme supplementation. In addition, birds fed with control diet with added enzyme showed negative feed intake, average live weight and body weight gain similar $(P>0.05)$ to the group fed with positive control diet with or without enzyme. It is concluded that the addition of exogenous enzymes in diets with reduced metabolizable energy, calcium and phosphorus, providing a feed intake, average live weight and weight gain similar to a diet with adequate levels for broiler.

Key words: poultry, phytase, amylase, protease, xilanase.

\section{INTRODUÇÃO}

A cadeia produtiva brasileira de frangos de corte evoluiu em consequência do melhoramento genético e dos avanços na área de nutrição, sanidade e manejo das aves. Esses avanços, de modo geral, têm

IDepartamento de Zootecnia, Faculdade de Ciências Agrárias e Veterinárias, Universidade Estadual Paulista (UNESP), 14884900, Jaboticabal, SP, Brasil. E-mail: sakomura@fcav.unesp.br. *Autor para correspondência.

IINorth Carolina State University, Raleigh, North Carolina. USA. 
permitido reduzir custos e melhorar a produtividade, com o intuito de manter destaque do país na competitividade em nível mundial (SARCINELLI et al., 2007).

Entre vários aspectos na produção avícola, a nutrição apresenta um papel importante, que abrange desde o conhecimento do potencial nutritivo dos nutrientes e exigências nutricionais. No potencial nutritivo, os programas nutricionais têm buscado novas estratégias para melhorar a digestibilidade dos alimentos e proporcionar condições que favoreçam a expressão do máximo potencial genético das aves, sem acréscimos aos custos de produção (ARAÚJO et al., 2007).

Nesse sentido, com o intuito de melhorar o aproveitamento dos nutrientes em dietas a base de milho e farelo de soja, adventos biotecnológicos, como as enzimas exógenas, têm sido utilizados na alimentação de monogástricos. As enzimas melhoram o desempenho dos animais por atuarem no aumento da digestibilidade dos nutrientes, além de diminuir a excreção de minerais, dentre os mais importantes o fósforo (FISCHER et al., 2002). Adicionalmente, as enzimas têm sido consideradas como componentes naturais alternativos que favorecem a redução do uso de antibióticos na alimentação animal. Esses componentes naturais, de modo geral, não só melhoram a condição do epitélio intestinal, como também atuam como moduladores na dieta. Além disso, o uso desses componentes atende à crescente preocupação da opinião pública mundial quanto à redução do uso de produtos químicos na alimentação animal (TEIXEIRA, 2007).

Um aspecto interessante e muitas vezes esquecido é que estratégias nutricionais podem ser estabelecidas com o uso de enzimas. Dentre essas, a redução do nível nutricional em dietas contendo enzimas pode aportar benefícios interessantes. Nessa manipulação nutricional, o intuído é obter uma resposta das aves similar ou até melhor comparada a uma dieta com níveis nutricionais adequados. Essa resposta é proporcionada pelo incremento do valor nutricional dos ingredientes, devido à atuação da enzima na melhora da disponibilidade de nutrientes.

Estudos relacionados à adição de enzimas em dietas de aves são numerosos. Entretanto, poucos avaliaram manipulações nutricionais com a adição de enzimas. Visto a importância desse aspecto, esta pesquisa teve por objetivo avaliar o efeito da combinação de enzimas comerciais fitase e complexo amilase, protease e xilanase, em dietas com ou sem redução dos níveis nutricionais, sobre o desempenho de frangos de corte.

\section{MATERIAL E MÉTODOS}

O presente experimento foi realizado no Setor deAvicultura do Departamento de Zootecnia da Faculdade de Ciências Agrárias e Veterinárias - UNESP, Campus de Jaboticabal - SP. Foram utilizados 1440 pintos de corte machos com um dia de idade da linhagem Cobb $500^{\circledR}$.

O delineamento experimental utilizado foi inteiramente casualizado em esquema fatorial 2x2 (duas dietas controles, com ou sem suplementação enzimática) com oito repetições e 45 aves em cada unidade experimental. As dietas controle foram: controle positivo com níveis nutricionais recomendados por ROSTAGNO et al. (2005) para atender às exigências para cada fase de criação, e um controle negativo com redução de 4,3 e 4,5\% de energia metabolizável(EM), 16,7 e 17,7\% de cálcio e 35 e 42,7\% de fósforo, nas fases inicial e de crescimento, respectivamente. A suplementação enzimática consistiu da combinação das seguintes enzimas, com inclusão de acordo com o fabricante: Avizyme $1500^{\circledR}\left(800 \mathrm{U} \mathrm{g}^{-1}\right.$ de xilanase, $2000 \mathrm{U} \mathrm{g}^{-1}$ de amilase e $6000 \mathrm{U} \mathrm{g}^{-1}$ de protease) com inclusão de $500 \mathrm{~g} \mathrm{t}^{-1}$; Phyzyme $\mathrm{XP}^{\circledR}\left(500 \mathrm{U} \mathrm{g}^{-1} \mathrm{de}\right.$ fitase) - com inclusão de $100 \mathrm{~g} \mathrm{t}^{-1}$.

A composição centesimal e os níveis calculados dos nutrientes das dietas controle para a fase inicial (1 a 21 dias de idade) e para fase de crescimento (22 a 42 dias de idade) são apresentados na tabela 1. Durante todo o período experimental, foram fornecidos água e ração à vontade.

Aos 21 e 42 dias de idade, as aves e as sobras de rações foram pesadas para mensuração das variáveis de desempenho: peso médio (PM), ganho de peso (GP), consumo médio de ração (CR) e conversão alimentar (CA). A mortalidade foi anotada diariamente para correção do consumo de ração das aves de cada parcela experimental.

As temperaturas $\left({ }^{\circ} \mathrm{C}\right)$ e umidades relativas (\%) foram anotadas diariamente e as médias semanais foram, respectivamente: $29,4^{\circ} \mathrm{C}$ e $58,4 \% ; 27,2^{\circ} \mathrm{Ce} 53,1 \% ; 25,7^{\circ} \mathrm{C}$ e 53,5\%; 23,9 e $53,5 \% ; 23,6^{\circ} \mathrm{C}$ e $54,1 \%$ e $22,7^{\circ} \mathrm{C}$ e $56 \%$.

Os dados obtidos foram submetidos à análise de variância incluindo no modelo os efeitos das dietas controles (DC), adição ou não de enzimas (E) e interação DC*E. As comparações de médias foram feitas utilizando o teste Tukey a 5\% de significância. As análises estatísticas foram realizadas através do programa SAS (2001).

\section{RESULTADOS E DISCUSSÃO}

Nas tabelas 2 e 3, são apresentados, respectivamente, os resultados de desempenho da fase inicial (1 a 21 dias) e do período total da criação (1 a 42 dias) de frangos de corte alimentados com as dietas com CP (controle positivo - níveis nutricionais adequados) ou CN (controle negativo - redução em 4,3\% de EM, 16,7\% Ca e 35\% P na fase inicial e 4,5\% de EM, $17,7 \%$ Ca e $42,4 \%$ P na fase de crescimento) contendo ou não enzimas exógenas. Nas duas fases 
Tabela 1 - Composição centesimal e os níveis calculados dos nutrientes das dietas basais para a fase inicial (1 a 21 dias de idade) e para fase de crescimento (22 a 42 dias).

\begin{tabular}{|c|c|c|c|c|}
\hline \multirow{2}{*}{ Ingredientes (\%) } & \multicolumn{2}{|c|}{ 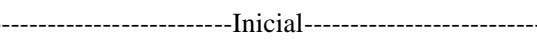 } & \multicolumn{2}{|c|}{ 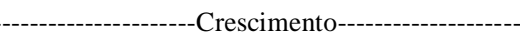 } \\
\hline & Controle Positivo & Controle Negativo & Controle Positivo & Controle Negativo \\
\hline Milho & 52,396 & 56,685 & 58,938 & 64,742 \\
\hline Farelo de Soja 45\% & 38,287 & 37,804 & 30,914 & 29,330 \\
\hline Gordura de aves & 4,579 & 1,624 & 5,648 & 2,169 \\
\hline Sal comum & 0,408 & 0,406 & 0,358 & 0,356 \\
\hline DL-Metionina (99\%) & 0,339 & 0,269 & 0,298 & 0,247 \\
\hline L-Lisina HCl (78\%) & 0,127 & 0,017 & 0,190 & 0,165 \\
\hline Calcário & 1,066 & 1,167 & 1,191 & 1,294 \\
\hline Fosfato Bicálcico & 1,563 & 0,793 & 1,228 & 0,462 \\
\hline Vitamina $^{1}$ & 0,025 & 0,025 & 0,025 & 0,025 \\
\hline Mineral $^{2}$ & 0,050 & 0,050 & 0,050 & 0,050 \\
\hline Anticoccidiano $^{3}$ & 0,050 & 0,050 & 0,050 & 0,050 \\
\hline Indicador $^{4}$ & 1,000 & 1,000 & 1,000 & 1,000 \\
\hline Inerte/enzima & 0,110 & 0,110 & 0,110 & 0,110 \\
\hline Total & 100,00 & 100,00 & 100,00 & 100,00 \\
\hline $\mathrm{EM}\left(\mathrm{kcal} \mathrm{kg}^{-1}\right)$ & 3052 & 2922 & 3200 & 3055 \\
\hline Proteína Bruta (\%) & 22,240 & 22,240 & 19,420 & 19,120 \\
\hline Cálcio & 0,900 & 0,750 & 0,850 & 0,700 \\
\hline Fósforo Disponível & 0,400 & 0,260 & 0,330 & 0,190 \\
\hline Metionina + cistina total & 1,010 & 0,950 & 0,900 & 0,850 \\
\hline Metionina total & 0,669 & 0,604 & 0,593 & 0,542 \\
\hline Lisina total & 1,290 & 1,200 & 1,150 & 1,100 \\
\hline Treonina total & 0,849 & 0,854 & 0,738 & 0,729 \\
\hline $\mathrm{Na}$ & 0,180 & 0,180 & 0,160 & 0,160 \\
\hline
\end{tabular}

${ }^{1}$ Suplemento vitamínico inicial com cada quilograma do produto contendo: ácido fólico 1000mg, ácido pantotênico 15000mg, antioxidante 0,5g, niacina 40000mg, selênio 300mg, biotina 60mg, vit B1 1800 mg, vit B12 12000mg, vit B2 6000 mg, vit B6 2800 mg, vit D3 2000000 UI, vit E $15000 \mathrm{mg}$, vit K3 $1800 \mathrm{mg}$. 'S Suplemento vitamínico crescimento com cada quilograma do produto contendo: ácido fólico $700 \mathrm{mg}$, ácido pantotênico 13000mg, antioxidante 0,5g, niacina 35000mg, selênio 300mg, vit B1 1600 mg, vit B12 10000mg, vit B2 5000 mg, vit B6 2600 mg, vit D3 1500000 UI, vit E $12000 \mathrm{mg}$, vit K3 $1500 \mathrm{mg} .{ }^{2}$ Suplemento mineral inicial/crescimento com cada quilograma do produto contendo: Manganês 150000mg, Zinco $100000 \mathrm{mg}$, Ferro $100000 \mathrm{mg}$, Cobre $16000 \mathrm{mg}$, Iodo $1500 \mathrm{mg}$. ${ }^{3}$ Monensina Sódica (20\%). ${ }^{4}$ Celite.

estudadas, houve interação $(\mathrm{P}<0,05)$ entre tipo de dietas e utilização ou não de enzimas para todas as variáveis de desempenho avaliadas, exceto para conversão alimentar (CA) das aves na fase inicial. O peso médio (PM) e ganho de peso (GP) das aves que receberam a dieta $\mathrm{CP}$, independente da suplementação enzimática, foram superiores $(\mathrm{P}<0,05)$ quando comparados às aves alimentadas com a dieta controle negativo. Entretanto, a suplementação enzimática melhorou $(\mathrm{P}<0,05)$ as características de desempenho das aves alimentadas com a dieta controle negativo. Nas aves alimentadas com dietas CN com suplementação enzimática, o CR, PM e GP foram 6,1; 9,8 e 10,2\% maiores $(\mathrm{P}<0,05)$, respectivamente, comparadas ao grupo alimentado com a dieta $\mathrm{CN}$ sem enzimas. Com relação a CA, não houve interação entre as dietas controle e a suplementação enzimática $(\mathrm{P}>0,05)$. A CA nas aves alimentadas com dieta CP foi 5,2\% melhor $(\mathrm{P}<0,05)$, comparada ao grupo alimentado com controle negativo. Nas aves alimentadas com dieta com suplementação enzimática, a CA foi 3,4\% melhor $(\mathrm{P}<0,05)$ em relação ao grupo com a dieta sem enzimas.

No período total, nas aves alimentadas com a dietaCN sem enzimas, oCR foi 6,35\%, o PM8,5\%, o GP 8,6\% e a CA $2,9 \%$ piores $(\mathrm{P}<0,05)$ quando comparadas ao grupo alimentado com $\mathrm{CN}$ com enzimas. Contudo, o desempenho das aves alimentadas com a dieta $\mathrm{CN}$ com a adição do complexo enzimático foi similar $(\mathrm{P}>0,05)$ às aves da dieta $\mathrm{CP}$ comenzimas, exceto para a CA, que foi $2,3 \%$ pior.

Diante dos resultados, o aumento no consumo de ração (6,06 e 5,97\%, nas fases inicial e total, respectivamente) na dieta $\mathrm{CN}$ suplementada com enzimas, refletiu na melhora do peso médio (9,84 e 8,47\%, nas fases inicial e total, respectivamente), e do ganho de peso das 
Tabela 2 - Médias e valores de P associados ao teste F da análise de variância do consumo de ração (CR), peso médio (PM), ganho de peso (GP) e conversão alimentar (CA) de frangos de corte alimentados com dietas com e sem redução dos níveis nutricionais, suplementadas ou não com enzimas, para frangos de corte na fase inicial (1 a 21 dias).

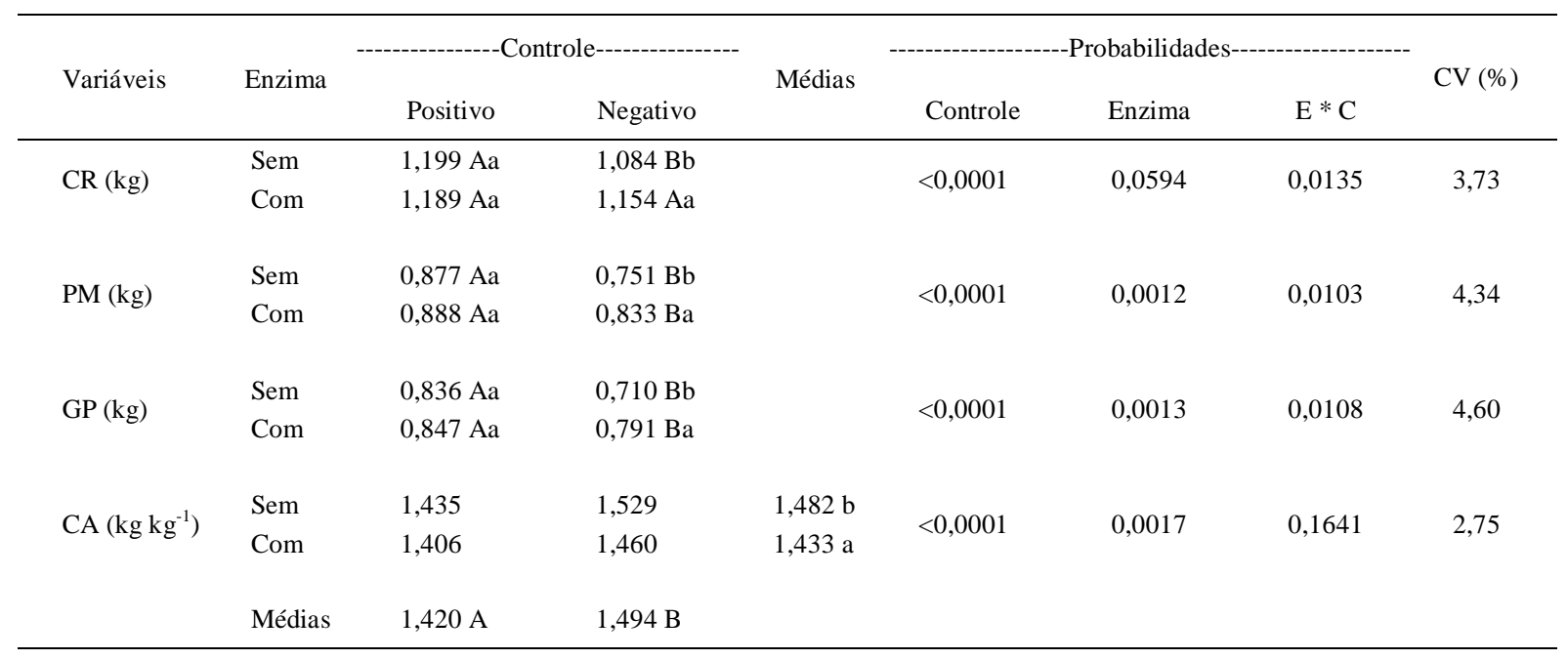

Médias seguidas de mesmas letras, maiúsculas nas linhas e minúsculas nas colunas, não diferem significativamente pelo teste de Tukey a 5\% de probabilidade.

aves (10,24 e8,64\%, nas fases inicial e total, respectivamente) quando comparado ao grupo do $\mathrm{CN}$ sem enzimas.

A melhora no desempenho das aves com o uso de enzimas nas dietas tem sido evidenciada em vários estudos (ZANELLA et al., 1999; COWIESON \& ADEOLA, 2005; OLUKOSI et al., 2007; BARBOSA et al., 2008; SANTOS et al., 2008). Entretanto, os benefícios no desempenho das aves com a utilização da combinação de enzimas é reflexo não apenas da melhoria no aproveitamento dos nutrientes, mas também da melhora no equilíbrio da microbiota bacteriana intestinal das aves. A utilização de enzimas exógenas reduz a quantidade de resíduo não digerido que entra no intestino grosso, como consequência do melhor aproveitamento de nutrientes no intestino delgado, reduzindo a população microbiana no íleo terminal (BEDFORD \& APAJALAHTI, 2001).

A melhora no GP e no CR com a suplementação enzimática no CN refletiu em benefícios na CA das aves na fase total de criação, que se traduziu em melhoria de 2,92\%. Adicionalmente, o desempenho das aves do $\mathrm{CN}$ com enzimas, com exceção da CA, foi similar ao CP com ou sem enzimas. CLEMENTINO et al. (2002) e COSTA et al. (2004) também observaram que a adição de enzimas (xilanase, amilase e protease) em dietas com níveis protéicos e energéticos reduzidos, contribui para um ganho de peso semelhante em relação às aves alimentadas com níveis nutricionais adequados. ZHOU et al. (2008) observaram que o GP, CR e CA das aves alimentadas com as dietas CN com a suplementação de fitase foi similar à dieta $\mathrm{CP}(\mathrm{P}<0,01)$ durante todo o período total da criação (1 a 48 dias). Esses resultados sugerem que a combinação de enzimas associada à manipulação nutricional na alimentação de aves pode ser benéfica em termos de redução de custo e excreção de nutrientes poluidores no meio ambiente.

O reduzido CR pelas aves do tratamento $\mathrm{CN}$ sem suplementação enzimática ocorreu, provavelmente, devido à deficiência de fósforo na dieta. Em dietas com redução nos níveis nutricionais, em geral, as aves buscam compensar a deficiência com aumento da ingestão. Entretanto, a deficiência em fósforo provoca diminuição no consumo de alimento (VIVEIROS et al., 2002), com consequente redução acentuada na síntese e liberação de hormônios de crescimento e hormônios da tireóide, principalmente $\mathrm{T}_{3}$ (PARMER et al., 1987). Por outro lado, a adição de fitase nas dietas provoca ruptura do complexo fósforo-ácido fítico, o que libera o mineral para ser absorvido e inativa o efeito depressor de sua deficiência sobre o consumo de ração (SANTOS et al., 2008). Portanto, a fitase melhora o aproveitamento do fósforo, o que reflete no aumento do CR e, consequentemente, na melhoria de outras variáveis de desempenho.

A suplementação enzimática na dieta CP não proporcionou efeito sobre o $\mathrm{CR}$, fato este explicado devido aos níveis nutricionais de tais dietas atenderem adequadamente às necessidades das aves. LEESON (1999) recomenda inclusão de fitase em dietas com níveis reduzidos de cálcio e fósforo. Entretanto, para obter os efeitos desejados da enzima, tais reduções não devem ser acentuadas. Frequentemente, é desconsiderada a eficiência 
Tabela 3 - Médias e valores de P associados ao teste F da análise de variância do consumo de ração (CR), peso médio (PM), ganho de peso (GP) e conversão alimentar (CA) de frangos de corte alimentados com dietas com e sem redução dos níveis nutricionais, suplementadas ou não com enzimas, para frangos de corte no período total de criação (1 a 42 dias).

\begin{tabular}{|c|c|c|c|c|c|c|c|}
\hline \multirow{2}{*}{ Variáveis } & \multirow{2}{*}{ Enzima } & \multicolumn{5}{|c|}{ 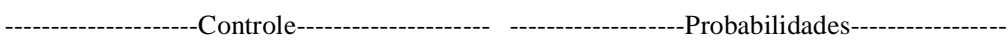 } & \multirow{2}{*}{ CV (\%) } \\
\hline & & Positivo & Negativo & Controle & Enzima & $\mathrm{E} * \mathrm{C}$ & \\
\hline \multirow{2}{*}{ CR (kg) } & Sem & $4,635 \mathrm{Aa}$ & $4,238 \mathrm{Bb}$ & \multirow{2}{*}{$<0,0001$} & \multirow{2}{*}{0,0511} & \multirow{2}{*}{0,0001} & \multirow{2}{*}{2,64} \\
\hline & Com & 4,536 Аа & 4,507 Аа & & & & \\
\hline \multirow{2}{*}{ PM (kg) } & Sem & 2,761 Аа & $2,400 \mathrm{Bb}$ & \multirow{2}{*}{$<0,0001$} & \multirow{2}{*}{0,0045} & \multirow{2}{*}{$<0,0001$} & \multirow{2}{*}{2,79} \\
\hline & Com & 2,698 Аа & 2,622 Aa & & & & \\
\hline \multirow{2}{*}{ GP (kg) } & Sem & 2,720 Аа & 2,358 Bb & \multirow{2}{*}{$<0,0001$} & \multirow{2}{*}{0,0045} & \multirow{2}{*}{$<0,0001$} & \multirow{2}{*}{2,84} \\
\hline & Com & 2,657 Аа & 2,581 Аа & & & & \\
\hline \multirow[t]{2}{*}{$\mathrm{CA}\left(\mathrm{kg} \mathrm{kg}^{-1}\right)$} & Sem & 1,704 Аa & 1,797 Bb & \multirow{2}{*}{$<0,0001$} & \multirow{2}{*}{0,0153} & \multirow{2}{*}{0,0070} & \multirow{2}{*}{1,50} \\
\hline & Com & 1,707 Аа & 1,746 Ba & & & & \\
\hline
\end{tabular}

Médias seguidas de mesmas letras, maiúsculas nas linhas e minúsculas nas colunas, não diferem significativamente pelo teste de Tukey a 5\% de probabilidade.

de utilização de complexos enzimáticos, uma vez que são utilizados mesmo em dietas que já atendam às necessidades das aves para expressar o máximo crescimento. Isso faz com que os nutrientes liberados pela ação enzimática não sejam aproveitados eficientemente pelo animal (SCHANG \&AZCONA, 2003). Nesse sentido, a redução da densidade nutricional da dieta com uso de enzimas pode trazer benefícios importantes por otimizar a eficiência das enzimas junto ao substrato.

Outro aspecto importante é que quando somente a fitase é adicionada na dieta, sua eficiência é reduzida devido à falta de acesso ao substrato, o qual se encontra no interior da matriz de polissacarídeos não amiláceos (PNAs) (DOURADO, 2008). As glicosidases (xilanases) são capazes de degradar a camada de PNAs da membrana, promovendo a despolimerização de arabinoxilanas, facilitando o acesso da fitase ao fitato armazenado na parede celular (OLUKOSI et al., 2007). Consequentemente, o acesso das enzimas endógenas e exógenas (amilase e protease) aos nutrientes encapsulados fica facilitado, o que aumenta a disponibilidade de nutrientes para o crescimento (NAGASHIRO, 2007). Vários estudos observaram esse efeito benéfico sobre as respostas das aves quando foram associadas várias enzimas na dieta. ZANELLA et al. (1999) atribuíram o aumento significativo no GP (2,2\%) das aves que receberam alimento contendo amilase, protease e xilanase em relação àquelas não suplementadas. COWIESON \& ADEOLA(2005) encontraram melhoria no ganho de peso de $14 \%$ com a combinação do complexo amilase, protease e xilanase com fitase em frangos de corte aos 28 dias de idade. BRITO et al. (2006), ao avaliarem a adição de complexo multienzimático observaram melhora no ganho de peso $(3,8 \%)$ e na conversão alimentar (4,24\%) na fase inicial. Entretanto, esses dados não condizem com LIMA et al. (2002), que não encontraram diferenças no consumo e na conversão alimentar no período de 1 a 42 dias de idade com suplementação de amilase e protease. OPALINSKI et al. (2006) também não encontraram diferenças nessas variáveis, suplementando com um complexo contendo xilanase, protease, glucanase e mannanase.

A combinação de enzimas exógenas em dietas de frangos de corte proporcionou resultados positivos no desempenho das aves em dietas manipuladas nutricionalmente. Tal fato sugere que a combinação do complexo enzimático (amilase, protease e xilanase com fitase) pode ser adotada em dietas com níveis nutricionais reduzidos, visando a manter o desempenho semelhante ao das aves alimentadas com dietas com densidade nutricional adequada.

\section{CONCLUSÃO}

A suplementação da combinação enzimática composta por xilanase, amilase, protease e fitase em dietas com níveis nutricionais reduzidos proporciona resultados de desempenho semelhante a aves alimentadas com uma dieta com níveis adequados, evidenciando a atuação das enzimas na liberação de nutrientes.

A suplementação enzimática em dietas com níveis nutricionais adequados não proporciona efeitos sobre o desempenho das aves, não justificando a suplementação over the top. 


\section{COMITÊ DE ÉTICA E BIOSSEGURANÇA}

Protocolo nํ 005587/11.

\section{REFERÊNCIAS}

BARBOSA, N.A.A. et al. Enzimas exógenas no desempenho e na digestibilidade ileal de nutrientes em frangos de corte. Pesquisa Agropecuária Brasileira, v.43, p.755-762, 2008. Disponível em: $<$ http://www.scielo.br/scielo.php?script=sci_arttext\&pid=S0100204X2008000600012\&lng=pt\&nrm=iso $>$. Acesso em: $16 \mathrm{dez}$. 2011. doi: 10.1590/S0100-204X2008000600012.

BEDFORD, M.R.; APAJALAHTI, J. Microbial interactions in the response to exogenous enzyme utilization. In: BEDFORD, M.R.; PARTRIDGE, G.G. Enzymes in farm nutrition. Londres: Cabi international, 2001. Cap.12, p.299-314.

BRITO, C.O. et al. Adição de complexo multienzimático em dietas à base de soja extrusada: valores energéticos e digestibilidade de nutrientes em pintos de corte. Revista Brasileira de Zootecnia, v.35, n.3, p.1047-1055, 2006. Disponível em: <http:/ /www.scielo.br/scielo.php?script $=$ sci_arttext\&pid $=$ S151635982006000400015>. Acesso em: 16 dez. 2011. doi: 10.1590/ S1516-35982006000400015.

FISCHER, G. et al. Desempenho de frangos de corte alimentados com dietas a base de milho e farelo de soja, com ou sem adição de enzimas. Revista Brasileira de Zootecnia, v.31, n.1, p.402-410, 2002. Disponível em: <http://www.scielo.br/scielo.php?pid=S151635982002000200015\&script=sci_arttext $>$. Acesso em: $16 \mathrm{dez}$. 2011. doi: 10.1590/S1516-35982002000200015.

CLEMENTINO, R.H. et al. Efeito dos níveis de enzimas sobre o desempenho de frangos de corte no período de 1 a 21 dias de idade. In: REUNIÃO ANUAL DA SOCIEDADE BRASILEIRA DE ZOOTECNIA, 39., 2002, Recife, PE. Anais... Viçosa: SBZ, 2002. CD-ROM.

COSTA, F.G. et al. Utilização de um complexo multienzimático em dietas de frangos de corte. Ciência Animal Brasileira, v.5 p.63-71, 2004. Disponível em: <http://www.revistas.ufg.br/ index.php/vet/article/view/326>. Acesso em: $18 \mathrm{dez} .2011$.

COWIESON, A.J.; ADEOLA, O. Carbohydrases, protease and phytase have an additive beneficial effect in nutritionally marginal diets for broiler chicks. Poultry Science, v.84, p.1860-1867, 2005. Disponível em: <http://www.ps.fass.org/content/84/12/ 1860.full.pdf $>$. Acesso em: 16 dez. 2011.

DOURADO, L.R.B. Enzimas exógenas em dietas para frangos de corte. 2008. 80f. Tese de Doutorado - Faculdade de Ciências Agrárias e Veterinárias, Universidade Estadual Paulista, Jaboticabal, SP.

LEESON, S. Enzimas para aves. In: SIMPÓSIO INTERNACIONAL SOBRE NUTRIÇÃO PARA AVES, 1999, Campinas, SP. Anais... Campinas: FACTA, 1999. p.173-185.

LIMA, A.C.F. et al. Avaliação do desempenho de frangos de corte alimentados com suplementação enzimática e probiótica. Ars Veterinaria, v.18, n.2, p.153-157, 2002. Disponível em: <www.arsveterinaria.org.br/arquivo/2002/v.18,\%20n.2.../153157.pdf>. Acesso em: 16 dez. 2011.

NAGASHIRO, C. Enzimas na nutrição de aves. In: CONFERENCIA APINCO, 2007, Santos, SP. Anais... Santos, FACTA, 2007. p.307-327.
OLUKOSI, O.A. et al. Age-related influence of a cocktail of xylanase, amylase, and protease or phytase individually or in combination in broilers. Poultry Science, v.86, p.77-86, 2007. Disponível em:<http://ps.fass.org/content/86/1/77.full>. Acesso em: 16 dez. 2011.

OPALINSKI, M. et al. Adição de níveis crescentes de complexo enzimático em rações com soja integral desativada para frangos de corte. Archives of Veterinary Science, v.11, n.3, p.31-35, 2006. Disponível em: <http://ojs.c3sl.ufpr.br/ojs2/index.php/ veterinary/article/viewArticle/7424>. Acesso em: 16 dez. 2011.

PARMER, T.G. et al. Thyroid function, growth hormone, and organ growth in broiler deficient in phosphorus. Poultry Science, v.66, p.1995-2004, 1987. Disponível em: <http:// ps.fass.org/content/66/12/1995.abstract>. Acesso em: $16 \mathrm{dez}$. 2011. doi: 10.3382/ps.0661995.

ROSTAGNO, H.S. et al. Tabelas brasileiras para aves e suínos. Composição de alimentos e exigências nutricionais. 2.ed. Viçosa, MG: UFV, 2005. 186p.

SANTOS, F.R. et al. Effect of phytase supplementation in diets on nutrient digestibility and performance in broiler chicks. Journal of Applied Poultry Reserch, v.17, p.191-201, 2008. Disponível em: <http://japr.fass.org/content/17/2/191.full>. Acesso em: 16 dez. 2011. doi: 10.3382/japr.2007-00028.

SARCINELLI, M.F. et al. Produção de frango de corte. Alegre: Pró-reitoria de extensão, UFES, 2007. 9p. (Boletim Técnico).

SAS INSTITUTE. Sas user's guide: statistics. Cary, 2003. 846p.

SCHANG, M. J.; AZCONA. J.O. Natural enzyme applications to optimize animal performance. In: NUTRITIONAL BIOTECHNOLOGY IN THE FEED AND FOOD INDUSTRIES OF ALLTECH ANNUAL MEETING,19., 2003, Lexington. Anais... Lexington: ALLTECH, 2003. p.163-170.

TEIXEIRA, M. Anátomo-clínica e biologia em frangos de corte experimentalmente infectados com eimeria acervulina e suplementados com betaína. 2007. 60f. Tese (Doutorado em Ciências Veterinárias) - Universidade Federal Rural do Rio de Janeiro, Seropédica, RJ.

VIVEIROS, A. et al. Effects of microbial phytase supplementation on mineral utilization and serum enzyme activities in broiler chicks fed different levels of phosphorus. Poultry Science, v.81, n.8, p.1172-1183, 2002. Disponível em: <http://ps.fass.org/content/81/8/1172.abstract>. Acesso em: 16 dez. 2011.

ZANELLA, I. et al. Effect of enzyme supplementation of broiler diets based on corn and soybeans. Poultry Science, v.78, n.4, p.561-568, 1999. Disponível em: <http://poultsci.highwire.org/ content/78/4/561.abstract>. Acesso em: 16 dez. 2011.

ZHOU, J.P. et al. Effects of a new recombinant phytase on the performance and mineral utilization of broilers fed phosphorusdeficient diets. Journal of Applied Poultry Reserch, v.17, p.331-339, 2007. Disponível em: <http://japr.fass.org/content/ 17/3/331.abstract>. Acesso em: 16 dez. 2011. doi: 10.3382/ japr.2007-00111. 